\title{
Diagmal: A Malaria Coactive Neuro-Fuzzy Expert System
}

\author{
Tinuke Omolewa Oladele ${ }^{1}$, Roseline Oluwaseun Ogundokun ${ }^{2(\triangle)}(\mathbb{D})$, \\ Joseph Bamidele Awotunde ${ }^{1}$ (D), Marion Olubunmi Adebiyi ${ }^{2}$ (D), \\ and Jide Kehinde Adeniyi ${ }^{2}$ \\ ${ }^{1}$ Department of Computer Science, University of Ilorin, \\ Ilorin, Kwara State, Nigeria \\ 2 Department of Computer Science, Landmark University Omu Aran, \\ Omu Aran, Kwara State, Nigeria \\ ogundokun. roseline@lmu. edu.ng
}

\begin{abstract}
In the process of clarifying whether a patient or patients is suffering from a disease or not, diagnosis plays a significant role. The procedure is quite slow and cumbersome, and some patients may not be able to pursue the final test results and diagnosis. The method in this paper comprises many fact-finding and data-mining methods. Artificial Intelligence techniques such as Neural Networks and Fuzzy Logic were fussed together in emerging the Coactive Neuro-Fuzzy Expert System diagnostic tool. The authors conducted oral interviews with the medical practitioners whose knowledge were captured into the knowledge based of the Fuzzy Expert System. Neuro-Fuzzy expert system diagnostic software was implemented with Microsoft Visual C\# (C Sharp) programming language and Microsoft SQL Server 2012 to manage the database. Questionnaires were administered to the patients and filled by the medical practitioners on behalf of the patients to capture the prevailing symptoms. The study demonstrated the practical application of neuro-fuzzy method in diagnosis of malaria. The hybrid learning rule has greatly enhanced the proposed system performance when compared with existing systems where only the back-propagation learning rule were used for implementation. It was concluded that the diagnostic expert system developed is as accurate as that of the medical experts in decision making. DIAGMAL is hereby recommended to medical practitioners as a diagnostic tool for malaria.
\end{abstract}

Keywords: Fuzzy inference system $\cdot$ Diagnosis $\cdot$ Expert system $\cdot$ Neuro-fuzzy modeling $\cdot$ Malaria

\section{Introduction}

Information and Communication Technology (ICT) based diagnostic tools were used in the diagnosis of specific illnesses such as malaria. Malaria is an extremely transmissible malady brought about by plasmodium, a gore organism [1, 2]. It is presently one of the foremost transmissible humid sicknesses that unpleasantly affect people's well-being and many developing countries' financial advancement, especially the sub-Saharan Africa (SSA). 
Malaria has been epidemic in our society since the dawn of history [3]. About $40 \%$ of the ecosphere's populace resides in rampant areas of malaria. Furthermore, $90 \%$ of instances and the bulk of mortalities occur in tropical Africa. Three million mortalities and 500 million medical instances were estimated yearly [4]. One of the major activities of W.H.O. is to make health care facilities available and accessible to all at all times and at various locations, but the current situation is the contrary. Most of the people who are to access these facilities are far removed from these facilities and resides farther from them or these facilities are too expensive to be accessed. In view of the foregoing, there is a necessity to provide a computerized system that is a knowledge-based system that will provide complementary medical services.

Several studies have shown that manual microscopy is not a reliable screening method unlike automated diagnosis [5-8]. An automated diagnosis system can be designed by understanding the diagnostic expertise $[9,10]$ for identifying malaria when prevailing symptoms are specified. An automated system aims at performing this task without human intervention and also provides an objective, reliable, and efficient tool to do so. Hence, Artificial Intelligence (AI) techniques based on neural network, fuzzy logic [11-17] and expert systems were applied in the diagnosis of malaria. These AI methods were used in place of the clinical laboratory in diagnosing malaria in patients.

This research was meant to showcase the prowess of the ICT approach to medical diagnosis. It will promote early diagonalization of malaria by making the diagnostic tool available and accessible to all even at the grass-root level. The ICT-based NeuroFuzzy Expert System diagnostic tool will optimize the activities of medical practitioners in the area of diagnosis of malaria. It will also assist academic institutions and the industry for the purpose of research.

In this research, the Coactive Neuro-Fuzzy Expert System diagnostic tool called DIAGMAL was designed and implemented. The diagnosis given by DIAGMAL is based on the prevailing symptoms given by the patients. Statistical Investigation of the datasets acquired after the administration of the questionnaires was also conveyed in order to establish the accuracy of the tool.

\section{Literature Review}

In the literature, ICT-based malaria diagnosis and some other diseases have been reported. In [18], fuzzy logic was employed and they developed a fuzzy expert malaria management system. Online system identification and management malaria was documented in [19], where a rule-based knowledgeable scheme was developed with the ability to interact with the scheme in real-time and via mobile devices based on the global mobile communication system (GSM) technology. Researchers [20] reported diamaltycin for malaria diagnosis and typhoid fever; a decision support system for medical application, a case-based decision support system for malaria and typhoid diagnosis. The study didn't apply the use of neural network and fuzzy logic algorithms. There was no precise method of distinguishing between malaria and typhoid. Decision support system model for diagnostic of tropical diseases using fuzzy logic was documented in [21], where fuzzy logic was used to diagnose tropical diseases such as malaria, typhoid, tuberculosis, sexually transmitted diseases, yellow fever, hepatitis B, 
leprosy and chickenpox. The confidence interval to give the assurance that the diagnosis given was actually for the specified disease was not computed.

[22] proposed a medical expert system for managing tropical diseases. In the proposed Medical Expert System (MES) the inference engine used a forward-looking chaining method to search the expert system for symptoms of a disease and it associate therapy which matches the query supplied by the patient.

[23] developed a flippant rule-based framework for tropical disease management. While assessing the extent of the tropical disease, fuzzy logic was employed. A fluffy expert system for hypertension management [9] was used to diagnose high blood pressure.

[24] provided a systematic empirical analysis of existing medical expert systems used to diagnose various diseases based on the increasing demand for human expert support systems. The study provided a descriptive overview of the different techniques used, such as rule-based, fuzzy, artificial neural networks, and smart hybrid models. The rule-based techniques were not too efficient based on its inability to learn. This required powerful search strategies for its knowledge-base. The fuzzy or ANN models are less efficient when compared to the hybrid models that can give a more accurate result.

[25] proposed an Adaptive Neuro Fuzzy Inference System (ANFIS) for malaria diagnosis. The system was designed to use the triangular membership function and as its learning algorithm used back propagation technique as well as the least square mean. The authors used the design of tagaki sugeno fuzzy inference to provide the system's rules base. The program result provided 98 percent accuracy in the identification of patients with malaria.

A decision support system centered on fuzzy logic was employed to diagnose tuberculosis [20]. In [26], a hybrid neuro-fuzzy expert scheme for the testing and forecast of thyroid disorders was conveyed in order to diagnose thyroid disorder. The system could be used for cases defined in the knowledge-based system since it was not an adaptive hybrid system.

This proposed system was therefore projected to develop a coactive neuro-fuzzy malaria diagnostic system tool, based on an adaptive neuro-fuzzy system model.

\section{Methodology}

\subsection{Questionnaire}

Questionnaire was designed for patients to capture their prevailing symptoms so as to be able to determine the presence or absence of malaria in their body system.

\section{Questionnaire Design}

The questionnaire designed for the diagnosis of malaria was subdivided into 3 sections.

i. Section A: Demographic and Socio-Economic characteristics of the respondents, such as; Age, sex, place of residence and so on was captured. 
ii. Section B: Symptoms of malaria, such as; fever, headache, Body pain, Catarrh, cough, nausea, chills, sweating, bitter taste, vomiting, jaundice, diarrhea, body weakness, sore throat were specified.

iii. Section C: Treatment of malaria. This section is meant to capture the preferred treatment measure by the respondent such as self-medication, use of herbs, or orthodox medical treatment and so on.

Population and Sample size

The target population for this study included the staff and students of the University of Ilorin Health Centre as well as the patients at the Civil Service Clinic in Ilorin, Kwara State, Nigeria. 180 respondents were the sample size used for this study and this includes 100 respondents from University of Ilorin Health Center (Staff and students inclusive) and 80 respondents from Civil Service Clinic Ilorin, Kwara State, Nigeria.

\section{Procedure for Questionnaire Administration}

Atotal number of 100 questionnaires were administered at the University of Ilorin Health Centre, while 80 copies were administered at the Civil Service Clinic in Ilorin. Out of the 100 copies of the questionnaire administered at the University of Ilorin Health Centre, 85 copies were returned while 23 copies were returned out of the 80 copies administered at the Civil Service Clinic, giving a total of 108 returned copies of the questionnaire.

\section{Results and Discussion}

Neuro-Fuzzy measures were adopted in the CANFES model which was used in the implementation of the proposed system DIAGMAL, the diagnostic tool for malaria disease. This section offers an in-depth analysis and interpretation of the results and discussion of the findings.

\subsection{Implementation of the Coactive Neuro-Fuzzy Expert System}

In this paper, the developed Coactive Neuro-Fuzzy Expert System tool for diagnosis of malaria was called DIAGMAL. Screenshots capturing all the interfaces representing the modules in the expert system are displayed in this section. The stages involved in entering the signs, symptoms and historical data, and the diagnosis being made were also captured.

\section{Splash Screen}

Figure 1 shows the splash screen for the expert system. The splash screen is a slide show of DIAGMAL logo.

\section{Patient Registration Page}

The patient record page captures the biodata of each patient as displayed in Fig. 2.

Figure 2 displays the registered patient records. When new users registered by inputting their data into the system, it is stored in a database and this page shows sample of some of the patients' records already stored in the application. 


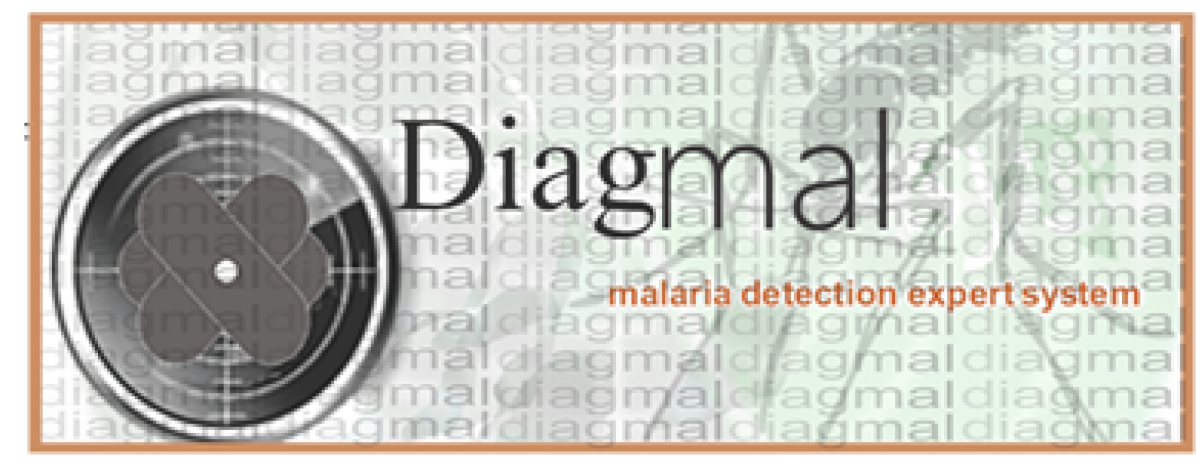

Fig. 1. DIAGMAL splash screen

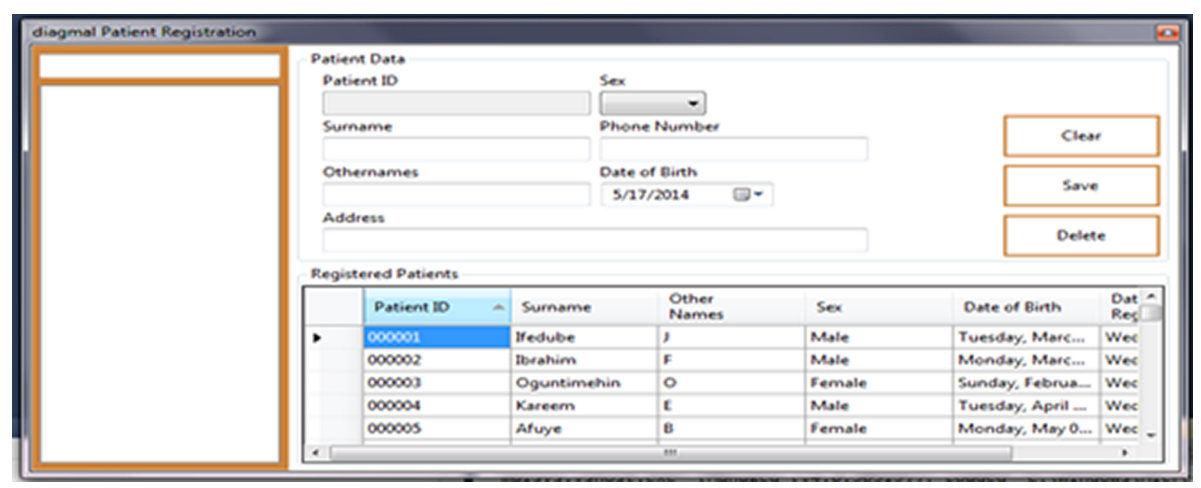

Fig. 2. Patient's registration form

\section{Expert System Initial Test}

This module captures the patient's historical and demographic data to a certain extent. The expert system then gives an assessment of the patient as being exposed to malaria based on the selected and entered data.

Figure 3 shows the expert system initial test. After the development of the application, the first implementation performed on the system is shown in this figure.

\section{Expert System General Test}

This module is divided into two columns, which are variable symptoms and selective symptoms. The variable symptoms are selected between a range of mild and high, while the selective symptoms are clicked as it applies to the patient.

Figure 4 shows the general test page. This is the page showing the general test which involves the variable symptoms. 


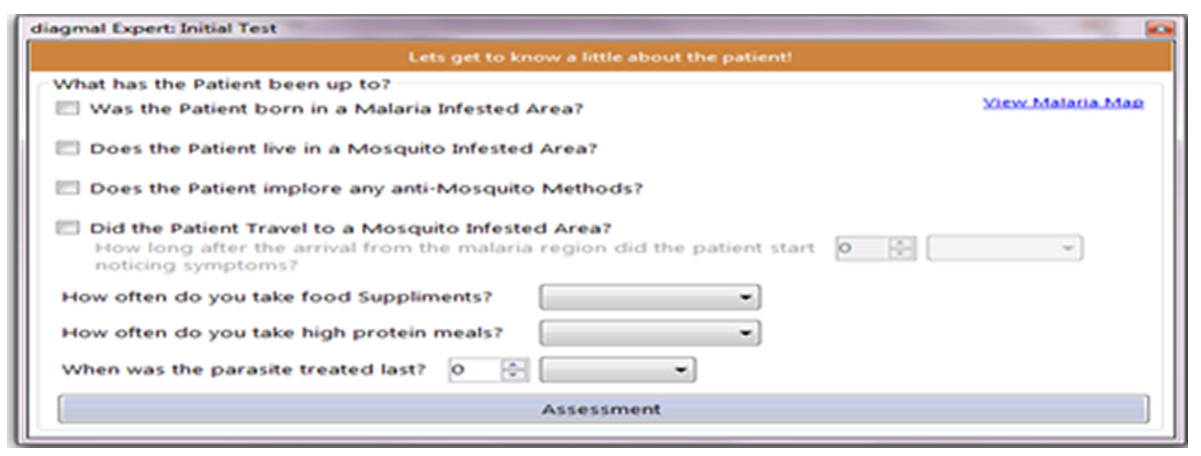

Fig. 3. Expert initial test

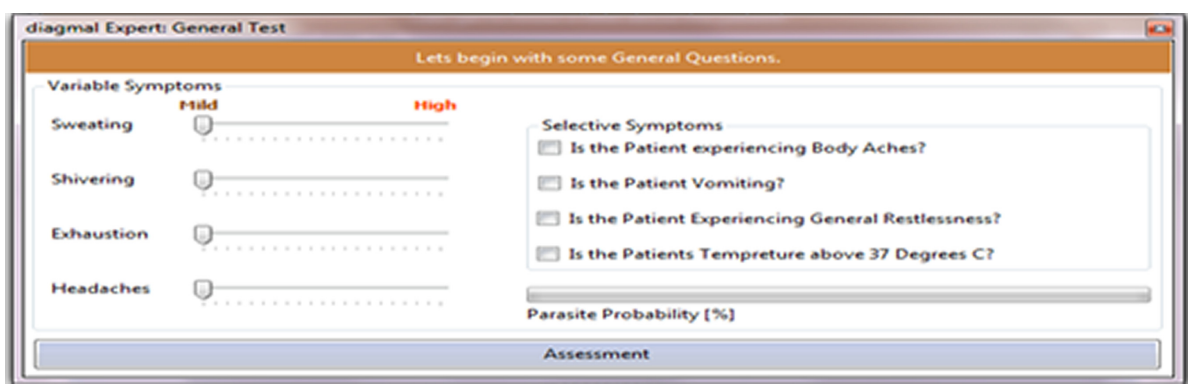

Fig. 4. General test

\section{Expert System Secondary Test}

This module contains variable symptoms where, body ache, extended cramps, and dizziness are captured between the range of mild and high. Respiratory rate is captured between normal and abnormal and lip texture is captured between normal and dry.

Figure 5 shows the secondary test which involves the variable symptoms but these symptoms are different from the ones in the general test page.

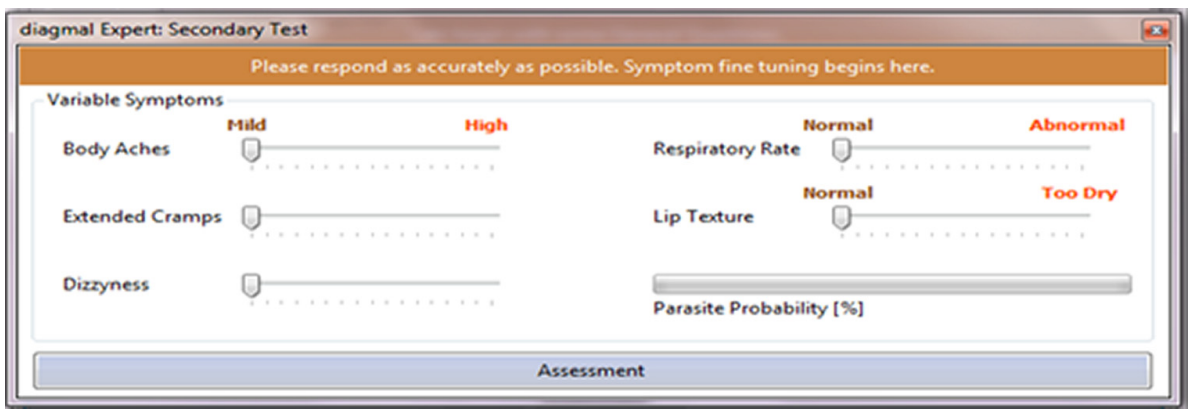

Fig. 5. Secondary test 


\section{Expert Final Test}

This module contains variable symptoms which are intended to capture all the possible signs and symptoms that are exhibited by the patient.

Figure 6 shows the final test page and this is the final test module for the application developed. These also contains different variables from the two initial pages.

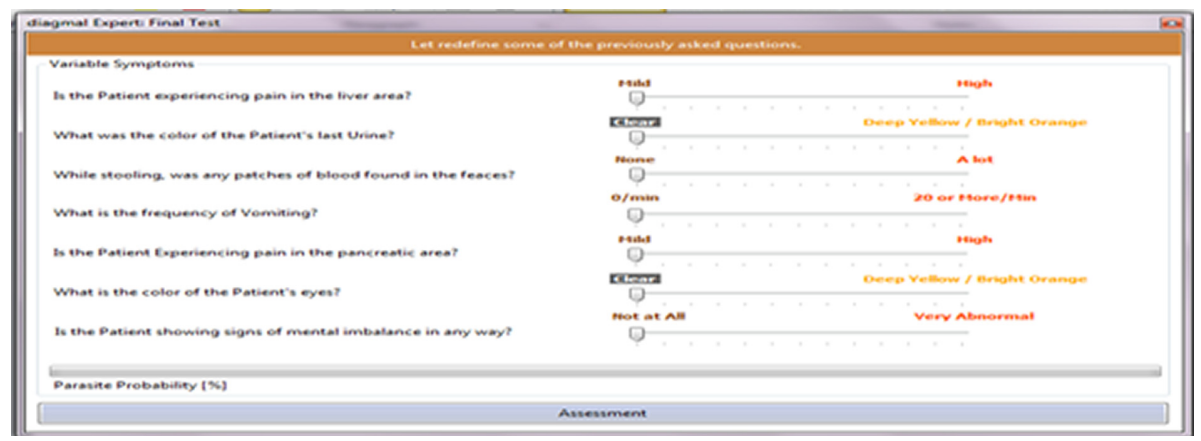

Fig. 6. Final test

\section{Inference Result}

This module serves as a link between the expert system result and the patient's biodata. The degree or intensity of malaria in the patient is displayed on this page.

Figure 7 shows the inference result. The inference setting was done and implementation was executed and Fig. 7 shows the outcome of the execution.

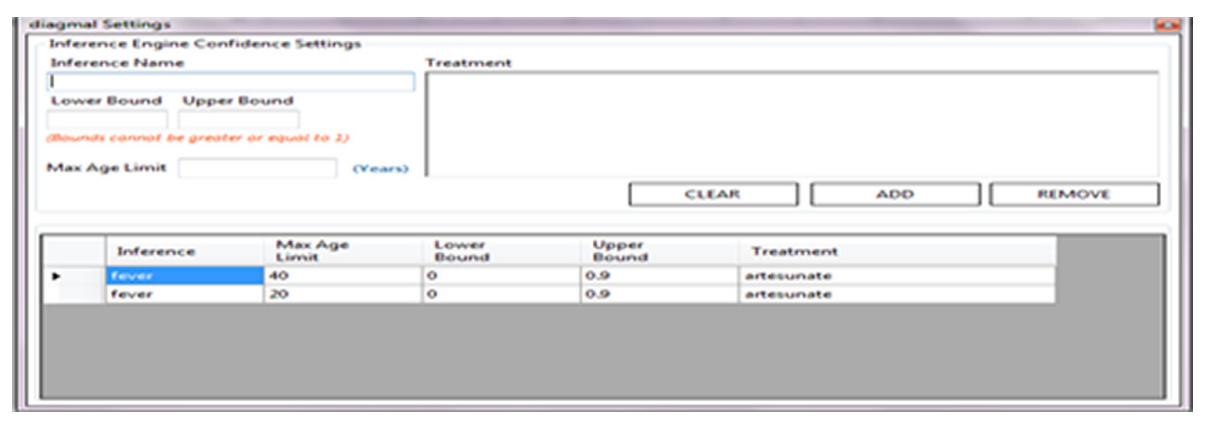

Fig. 7. Inference result

\section{Report Engine}

This module generates the patient's details with their respective diagnosis result. The result can then be printed by the administrator or the user.

Figure 8 shows the report engine. When a report scope is clicked, it displays reports about patients. 


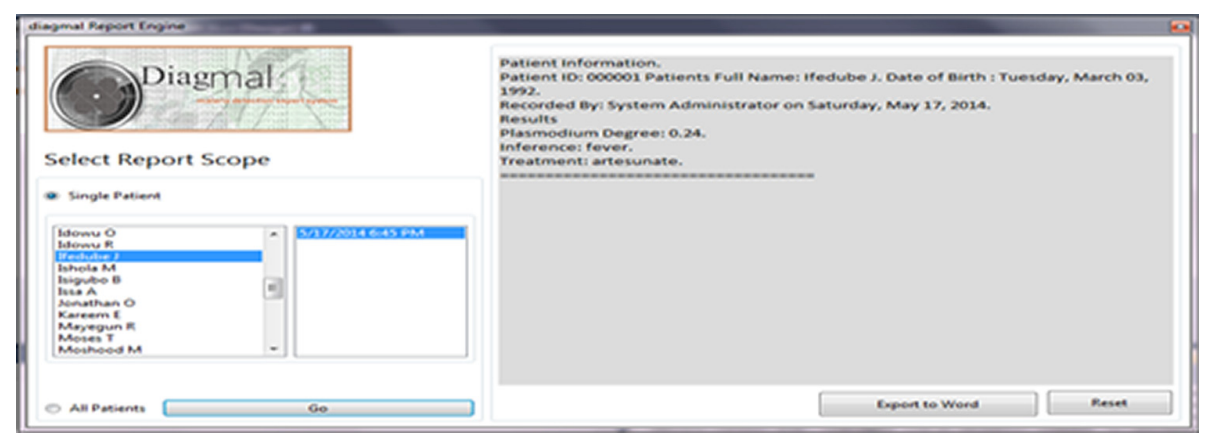

Fig. 8. Report engine

\subsection{Questionnaire Data Analysis and Interpretation}

The Demographic and Socio-economic Characteristics of the Respondents is shown in Table 1.

Table 2 shows that the average age of the respondents was 27.08 years (27 years). Also, it is obvious from the same table that expected monthly income of the respondents was 58,300 Naira. $37.3{ }^{\circ} \mathrm{C}$ was estimated to be the average body temperature of the respondents as at the time of investigation. With respect to the question relating to the frequency of malaria per year, most of the respondents claimed that they had malaria three times per year. A respondent affirmed that he/she has not had malaria before, whereas someone said that he/she had malaria ten times in a year.

Table 3 shows that almost all of the respondents had been diagnosed for malaria fever before survey $(99.1 \%)$. Only one respondent $(0.9 \%)$ said that he/she had never been a patient of malaria. One - fourth of those who claimed that they had been diagnosed for malaria before $(26.9 \%)$ were still having malaria as at the time of survey. Almost four out of every five respondents $(76.9 \%)$ asserted that their malaria cases were seldom. Nearly one - fifth of the respondents $(18.5 \%)$ claimed that they had malaria fever frequently. The distribution of respondents according to the symptoms of malaria shows that two out of every five respondents $(39.8 \%)$ said that headache was the most severe symptom of malaria. This is followed by those who claimed that body pain and fever were the major symptoms of malaria (18.5\% and $17.5 \%$ respectively). Vomiting and Jaundice had the least representations (0.9\%). This implies that both vomiting and jaundice were not the main symptoms of malaria. Only $4.6 \%$ of the respondents did not respond to the question relating to most severe symptoms of malaria at all. This is evident by the following bar chart depicted in Fig. 9.

It is evident by the following bar chart depicted by Fig. 9 that $15.7 \%$ of respondents have fever as their own symptoms of malaria, 39.8\% have headache as their own symptoms, $16.7 \%$ have body pain as their own symptoms of malaria, $7.4 \%$ have catarrh as their own symptoms of malaria, $1.9 \%$ have chill as their own symptoms of malaria, $0.9 \%$ symptoms is vomiting and jaundice as their own symptoms of malaria, $1.9 \%$ have diarrhea as their own symptoms of malaria, $8.3 \%$ have body weakness as their own 
Table 1. Demographic and socio-economic characteristics of the respondents

\begin{tabular}{|c|c|c|}
\hline Characteristics & Number & Percentage \\
\hline \multicolumn{3}{|l|}{ Age } \\
\hline $15-24$ & 66 & 61.1 \\
\hline $25-34$ & 23 & 21.3 \\
\hline $35-44$ & 4 & 3.7 \\
\hline $45-54$ & 8 & 7.4 \\
\hline 55 and above & 5 & 4.6 \\
\hline No response & 2 & 1.9 \\
\hline Total & 108 & 100.0 \\
\hline \multicolumn{3}{|l|}{ Sex } \\
\hline Male & 60 & 55.6 \\
\hline Female & 47 & 43.5 \\
\hline No response & 1 & 0.9 \\
\hline Total & 108 & 100.0 \\
\hline \multicolumn{3}{|l|}{ Marital status } \\
\hline Single & 83 & 76.9 \\
\hline Ever married & 25 & 23.1 \\
\hline Total & 108 & 100.0 \\
\hline \multicolumn{3}{|l|}{ Education } \\
\hline Primary & 3 & 2.8 \\
\hline Secondary & 13 & 12.0 \\
\hline First degree & 72 & 66.7 \\
\hline Higher degree & 7 & 6.5 \\
\hline Undergraduate & 8 & 7.4 \\
\hline No response & 5 & 4.6 \\
\hline Total & 108 & 100.0 \\
\hline \multicolumn{3}{|l|}{ Place of residence } \\
\hline Urban & 96 & 88.9 \\
\hline Rural & 12 & 11.1 \\
\hline Total & 108 & 100.0 \\
\hline \multicolumn{3}{|l|}{ Occupation } \\
\hline Civil/public servant & 12 & 11.1 \\
\hline Private salary employee & 3 & 2.8 \\
\hline Self-employed & 13 & 12.0 \\
\hline Artisan & 2 & 1.9 \\
\hline Student & 66 & 61.1 \\
\hline No response & 12 & 11.1 \\
\hline Total & 108 & 100.0 \\
\hline \multicolumn{3}{|l|}{ Hospitals used } \\
\hline Unilorin health services & 85 & 78.7 \\
\hline Civil service clinic & 23 & 21.3 \\
\hline Total & 108 & 100.0 \\
\hline
\end{tabular}

Source: Survey, 2019. 
Table 2. Summary of quantitative data

\begin{tabular}{l|l|l|l}
\hline Characteristics & Minimum & Maximum & Mean \\
\hline Age & 16 & 89 & 27.08 \\
\hline Income & 1000 & 699000 & 58300 \\
\hline Body temp & $23{ }^{\circ} \mathrm{C}$ & $42{ }^{\circ} \mathrm{C}$ & $37.3{ }^{\circ} \mathrm{C}$ \\
\hline Malaria per year & N/A & 10 & 3.0 \\
\hline
\end{tabular}

Source: Survey, 2019.

symptoms of malaria, $1.9 \%$ have sore throat as their own symptoms of malaria and lastly $4.6 \%$ respondents didn't give any response.

According to doctor's reports, more than three out of every five respondents $(72.2 \%)$ were diagnosed for malaria fever at the time of the investigation. This is followed by those who were diagnosed with plasmodiasis (3.2\%). Exactly one - fourth of the doctors $(25.0 \%)$ did not indicate the current diagnosis of their patients. Only one patient was diagnosed with hypertension. The distribution of respondents according to hospital attendance for malaria treatment indicates that more than three out of every five respondents $(63.0 \%)$ claimed that they attended hospital for malaria treatment while $31.5 \%$ of the respondents did not attend hospital for malaria treatment. Table 3 also shows that approximately one out of every five respondents (18.5\%) preferred selfmedication to attend the hospital. This is followed by those who said that they preferred orthodox medication (17.6\%). More than the average of the respondents $(57.4 \%) \mathrm{did}$ not indicate their preference at all. It is obvious from the table that two out of every five respondents $(41.7 \%)$ indicated tablets as what they used to treat malaria, while one fifth of the respondents $(21.3 \%)$ claimed that they used injections to cure malaria. But one - fourth of the respondents $(25.9 \%)$ combined tablets with injections for malaria treatment.

\section{Discussion of Results}

\subsection{Implementation of the Coactive Neuro-Fuzzy Expert System}

The identification given by the expert system named DIAGMAL showed the exact diagnosis given by the doctor. This specifies that computer application can accurately determine the diagnosis of malaria. The essence of this research is to determine the extent to which neuro-fuzzy methodology represents the exact diagnosis of patients compared to that of physicians. Accuracy of the system was tested by observations made from the various populations which were assessed on the field. Based on the assessment, it was found that DIAGMAL gave accurate diagnostic predictions.

There are two platforms on which this application can be implemented. It can be implemented as a web-based application or as a desktop application. The expert system was developed as a desktop application that can be implemented on any personal 
Table 3. Symptoms of malaria

\begin{tabular}{|c|c|c|}
\hline Characteristics & Number & Percentage $(\%)$ \\
\hline \multicolumn{3}{|c|}{ Ever diagnosed for malaria } \\
\hline Yes & 107 & 99.1 \\
\hline No & 1 & 0.9 \\
\hline Total & 108 & 100.0 \\
\hline \multicolumn{3}{|c|}{ Currently diagnosed for malaria } \\
\hline Yes & 29 & 26.9 \\
\hline No & 74 & 68.5 \\
\hline No response & 5 & 4.6 \\
\hline Total & 108 & 100.0 \\
\hline \multicolumn{3}{|c|}{ Frequency of malaria } \\
\hline Seldom & 83 & 76.9 \\
\hline Frequently & 20 & 18.5 \\
\hline Very frequently & 2 & 1.9 \\
\hline No response & 3 & 2.8 \\
\hline Total & 108 & 100.0 \\
\hline \multicolumn{3}{|c|}{ Most severe symptoms of malaria } \\
\hline Fever & 17 & 15.7 \\
\hline Headache & 43 & 39.8 \\
\hline Body pain & 18 & 16.7 \\
\hline Catarrh & 8 & 7.4 \\
\hline Chill & 2 & 1.9 \\
\hline Vomiting & 1 & 0.9 \\
\hline Jaundice & 1 & 0.9 \\
\hline Diarrhea & 2 & 1.9 \\
\hline Body weakness & 9 & 8.3 \\
\hline Sore throat & 2 & 1.9 \\
\hline No response & 5 & 4.6 \\
\hline Total & 108 & 100.0 \\
\hline \multicolumn{3}{|c|}{ Doctors' current diagnosis } \\
\hline Malaria fever & 78 & 72.2 \\
\hline Plasmadiasis & 4 & 3.7 \\
\hline Hypertension & 1 & 0.9 \\
\hline No response & 25 & 23.1 \\
\hline Total & 108 & 100.0 \\
\hline \multicolumn{3}{|c|}{ Hospital's attendance for malaria treatment } \\
\hline Yes & 107 & 63.0 \\
\hline No & 34 & 31.5 \\
\hline No response & 6 & 5.6 \\
\hline Total & 108 & 100.0 \\
\hline
\end{tabular}


Table 3. (continued)

\begin{tabular}{|c|c|c|}
\hline Characteristics & Number & Percentage $(\%)$ \\
\hline \multicolumn{3}{|l|}{ Malaria treatment methods } \\
\hline Self-medication & 20 & 18.5 \\
\hline Herbs & 6 & 5.6 \\
\hline Orthodox medical treatment & 19 & 17.6 \\
\hline Other treatments & 1 & 0.9 \\
\hline No response & 62 & 57.4 \\
\hline Total & 108 & 100.0 \\
\hline \multicolumn{3}{|l|}{ Malaria treatments preference } \\
\hline Tablets & 45 & 41.7 \\
\hline Injections & 23 & 21.3 \\
\hline Tablets and injections combined & 28 & 25.9 \\
\hline Herbs & 4 & 3.7 \\
\hline No response & 8 & 7.4 \\
\hline Total & 108 & 100.0 \\
\hline
\end{tabular}

Source: Survey, 2019.

\section{8 \\ Symptoms of Malaria}

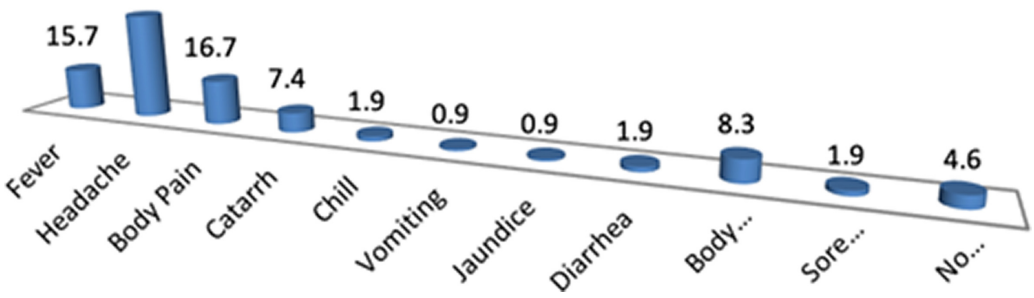

Fig. 9. Symptoms of Malaria

computer. Hence, the problem of internet connectivity has been overcome. This also specifies that the neuro-fuzzy expert system diagnostic tool can be truly deployed and made accessible at the grass-root level.

\subsection{Summary of Findings}

a. Design and implementation of a Coactive Neuro-Fuzzy Expert System diagnostic tool called DIAGMAL.

b. Empirically, the symptoms of malaria were identified;

c. The most severe symptoms of malaria were identified; and

d. It was deduced that even though headache, body pain, fever and other symptoms identified by the respondents (that is, patients) are symptoms of malaria, they are also symptoms of other diseases. 


\section{Conclusion}

The need to develop a system that would assist physicians in the diagnosis of malaria cannot be over emphasized. This paper demonstrated the practical application of information and communication technology in the medical domain. It has employed the use of a coactive neuro-fuzzy expert system that can help in the diagnosis of malaria. The system is an interactive system that predicts the intensity of malaria in a patient.

The hybrid learning rule enhances the performance of the system. Based on these results, the study shows that the ICT-based Neuro-Fuzzy Expert System for diagnosis of malaria produces accurate results. DIAGMAL is hereby recommended to the world of academia and the industry for the purpose of research and to assist medical practitioners as a diagnostic tool for malaria.

\section{Availability of Data and Material}

The datasets used in this study were gotten from a survey and deposited in Zenodo Database repository [27].

\section{References}

1. Adebiyi, M., et al.: Computational investigation of consistency and performance of the biochemical network of the malaria parasite, plasmodium falciparum. In: Misra, S., et al. (eds.) ICCSA 2019. LNCS, vol. 11623, pp. 231-241. Springer, Cham (2019). https://doi. org/10.1007/978-3-030-24308-1_19

2. Carter, R., Mendes, K.N.: Evolutionary and historical aspects of the burden of malaria. Clin. Microbiol. Rev. 15, 564-594 (2002)

3. White, N.J.: Antimalarial drug resistance. J. Clin. Invest. 113, 1084-1092 (2004)

4. Kettelhut, M.M., Chiodini, P.L., Edwards, H., Moody, A.: External quality assessment schemes raise standards: evidence from UKNEQAS parasitology subschemes. J. Clin. Pathol. 56, 927-932 (2003)

5. Coleman, R.E., et al.: Comparison of field and expert laboratory microscopy for active surveillance for asymptomatic Plasmodium falaparum and Plasmodium vivax in western Thailand. Am. J. Trop. Med. Hyg. 67, 144-154 (2002)

6. Bates, I., Bekoe, V., Asamoa-Adu, A.: Improving the accuracy of malaria-related laboratory tests in Ghana. Malar. J. 3 (2004). Article number: 38. https://doi.org/10.1186/1475-2875-338

7. Mitiku, K., Mengistu, G., Gelaw, B.: The reliability of blood film examination for malaria at the peripheral health unit. Ethiop. J. Health Dev. 17, 197-204 (2003)

8. Adebayo, O., Asani, E.O., Ogundokun, R.O., Ananti, E.C., Adegun, A.: A neuro-fuzzy based system for the classification of cells as cancerous of non-cancerous. Int. J. Med. Res. Health Sci. 7(5), 155-166 (2018)

9. Djam, X.Y., Kimbi, Y.H.: Fuzzy expert system for the management of hypertension. Pac. J. Sci. Technol. 12(1), 390-402 (2011)

10. Donfack, A.F., Abdullahi, M., Ezugwu, A.E., Alkali, S.A.: Online system for diagnosis and treatment of malaria (2009) 
11. Lala, O.G., Emuoyibofarhe, O.J., Fajuyigbe, O., Onaolapo, S.O.: Diamaltycin for the diagnosis of malaria and typhoid fever: a decision support system for medical application. In: Proceedings of the First International Conference on Mobile Computing, Wireless Communication, E-Health, M-Health \& Telemedicine (MWEMTem 2008), Held at Ladoke Akintola University of Technology (LAUTECH), Ogbomosho (2008)

12. Olabiyisi, S.O., Omidiora, E.O., Olaniyan, M.O., Dorikoma, O.: A decision support system model for diagnosing tropical diseases using fuzzy logic. Afr. J. Comput. ICT 4(2), 1-6 (2011)

13. Adekoya, A.F., Akinwale, A.T., Oke, O.E.: A medical expert system for managing tropical diseases. In: Proceedings of the Third Conference on Science and National Development, pp. 74-86 (2008)

14. Obot, O.U., Uzoka, F.M.E.: Fuzzy rule-based framework for the management of tropical diseases. Int. J. Eng. Inform. 1(1), 7-17 (2008)

15. Imhanlahimi, R.E., John-Otumu, A.M.: Application of expert system for diagnosing medical conditions: a methodological review. Eur. J. Comput. Sci. Inf. Technol. 7(2), 12-25 (2019)

16. Osubor and Chiemeke: An adaptive neuro fuzzy inference system for the diagnosis of malaria. NISEB J. 14(4), 212-222 (2015)

17. Agboizebeta, I.A., Chukwuyeni, O.J.: Application of neuro-fuzzy expert system for the probe and prognosis of thyroid disoder. Int. J. Fuzzy Log. Syst. (IJFLS) 2(2), 1-11 (2012)

18. Ayo, F.E., et al.: A fuzzy based method for diagnosis of acne skin disease severity. iManager's J. Pattern Recogn. 5(2), 10 (2018)

19. Awotunde, J.B., Matiluko, O.E., Fatai, O.W.: Medical diagnosis system using fuzzy logic. Afr. J. Comput. ICT 7(2), 99-106 (2014)

20. Jimoh, R.G., Afolayan, A.A., Awotunde, J.B., Matiluko, E.O.: Fuzzy logic based expert system in the diagnosis of Ebola virus. Ilorin J. Comput. Sci. Inf. Technol. 2(1), 73-94 (2017)

21. Thompson, T., Sowunmi, O., Misra, S., Fernandez-Sanz, L., Crawford, B., Soto, R.: An expert system for the diagnosis of sexually transmitted diseases-ESSTD. J. Intell. Fuzzy Syst. 33(4), 2007-2017 (2017)

22. Azeez, N.A., et al.: A fuzzy expert system for diagnosing and analyzing human diseases. In: Abraham, A., Gandhi, N., Pant, M. (eds.) IBICA 2018. AISC, vol. 939, pp. 474-484. Springer, Cham (2019). https://doi.org/10.1007/978-3-030-16681-6_47

23. Lawanya Shri, M., Ganga Devi, E., Balusamy, B., Kadry, S., Misra, S., Odusami, M.: A fuzzy based hybrid firefly optimization technique for load balancing in cloud datacenters. In: Abraham, A., Gandhi, N., Pant, M. (eds.) IBICA 2018. AISC, vol. 939, pp. 463-473. Springer, Cham (2019). https://doi.org/10.1007/978-3-030-16681-6_46

24. Alhassan, J.K., Misra, S., Umar, A., Maskeliūnas, R., Damaševičius, R., Adewumi, A.: A fuzzy classifier-based penetration testing for web applications. In: Rocha, Á., Guarda, T. (eds.) ICITS 2018. AISC, vol. 721, pp. 95-104. Springer, Cham (2018). https://doi.org/10. 1007/978-3-319-73450-7_10

25. Ayo, F.E., Awotunde, J.B., Ogundokun, R.O., Folorunso, S.O., Adekunle, A.O.: A decision support system for multi-target disease diagnosis: a bioinformatics approach. Heliyon 6(3), $\mathrm{e} 03657$ (2020)

26. Jimoh, R.G., Awotunde, J.B., Babatunde, A.O., Ameen, A.O, James, T.R., Fatai, O.W.: Simulation of medical diagnosis system for malaria using fuzzy logic. Int. J. Inf. Process. Commun. (IJIPC) 2(1) (2014)

27. Oladele, T.O., Ogundokun, R.O., Adebiyi, M.O.: Datasets on malaria disease [data set]. Zenodo (2019). http://doi.org/10.5281/zenodo.3592442 